\title{
Appraisal Antecedents of Shame and Guilt: Support for a Theoretical Model
}

\author{
Jessica L. Tracy \\ University of British Columbia \\ Richard W. Robins \\ University of California, Davis
}

Four studies used experimental and correlational methods to test predictions about the antecedents of shame and guilt derived from an appraisal-based model of self-conscious emotions (Tracy E Robins, 2004). Results were consistent with the predicted relations between appraisals (i.e., causal attributions) and emotions. Specifically, (a) internal attributions were positively related to both shame and guilt; (b) the chronic tendency to make external attributions was positively related to the tendency to experience shame; and (c) internal, stable, uncontrollable attributions for failure were positively related to shame, whereas internal, unstable, controllable attributions for failure were positively related to guilt. Emotions and attributions were assessed using a variety of methods, so converging results across studies indicate the robustness of the findings and provide support for the theoretical model.

Keywords: guilt; shame; causal attribution; self-conscious emotion; appraisal

W hen former Senator Bob Kerrey publicly acknowledged that he had ordered soldiers to murder innocent civilians during the Vietnam War, he told a reporter, "It's far more than guilt. It's the shame. You can never, can never get away from it. It darkens your day" (Vistica, 2001). Kerrey chose his words carefully and emphasized a distinction between two seemingly similar self-conscious emotions-guilt and shame. Despite the traditional view that these "are one and the same affect" (Tomkins, 1963), recent research is more consistent with Kerrey's conception that guilt and shame are distinct emotions that promote divergent functional outcomes. Guilt has been linked to prosocial and reparative behaviors, whereas shame has been linked to hiding and social withdrawal (Tangney \& Dearing, 2002).
Yet, there are few antecedent events that uniquely elicit either shame or guilt (Keltner \& Buswell, 1996; Tangney, 1992). How is it possible for two emotions to be functionally distinct yet result from the same antecedent events? Theorists have resolved this issue by suggesting that it is not the events, per se, that determine which emotion is experienced but rather how events are appraised (e.g., Lazarus, 1991).

\section{APPRAISAL MODEL OF SELF-CONSCIOUS EMOTIONS}

We recently proposed an appraisal-based model of selfconscious emotions (Tracy \& Robins, 2004; Tracy \& Robins, in press) in which shame, guilt, pride, and embarrassment are elicited by cognitive appraisals about the emotion-eliciting event's implications for one's identity and causal attributions for event. These attributions determine whether self-conscious or non-self-conscious emotions occur and, if self-conscious, which emotion occurs. The present research uses diverse methodologies, both correlational and experimental, to test three broad hypotheses generated from our model and thereby helps resolve inconsistencies about the antecedents of shame and guilt.

\section{The Elicitation of Self-Conscious Emotions}

Self-conscious emotions critically involve self-evaluative processes, whereas non-self-conscious (e.g., anger, fear)

Authors' Note: Please address correspondence to Jessica L. Tracy, University of British Columbia, Department of Psychology, 2136 West Mall, Vancouver, BC, V6T 1Z4, Canada; e-mail: jltracy@psych.ubc.ca.

PSPB, Vol. 32 No. 10, October 2006 1339-1351

DOI: $10.1177 / 0146167206290212$

(C) 2006 by the Society for Personality and Social Psychology, Inc. 
can involve such processes but need not. To experience a self-conscious emotion, an individual must reflect on his or her stable self-representations and determine how the emotion-eliciting event is relevant to those representations (M. Lewis, 2000; Tracy \& Robins, 2004). After self-representations are activated, a series of causal attributions must be made. The first of these is the attribution of locus, which concerns whether events are caused by factors internal or external to the individual. Our model proposes that self-conscious emotions occur when events are attributed to internal causes-the self. Thus, our first prediction states: Internal attributions will lead to self-conscious emotions, such as shame and guilt (Hypothesis 1).

Support for this prediction is mixed. Several studies manipulating attributions for a hypothetical failure found a positive relation between internal attributions and shame and guilt (e.g., Hudley, 1992; Kuppens, Van Mechelen, Smits, \& De Boek, 2003; Roseman, 1991; Russell \& McAuley, 1986; Weiner, Graham, \& Chandler, 1982). However, studies assessing actual attributions for college grades failed to support this link (e.g., Russell \& McAuley, 1986, Study 2), and in a study examining chronic attributional styles and emotional dispositions, the effect did not hold for guilt (Tangney, Wagner, \& Gramzow, 1992).

\section{Shame and External Attributions}

According to our model, external attributions lead to non-self-conscious emotions such as anger. However, a more complex process is suggested by the finding that externalizing blame (i.e., making external attributions for negative events) is positively related to shame (Tangney \& Dearing, 2002). It is important in this context to distinguish between the attributions that elicit an emotion and the regulatory response that follows the experience of a painful emotion such as shame. Individuals who repeatedly experience shame may learn to regulate it by making external attributions. The intensity of shame and its strong negative impact on self-esteem promote its frequent regulation (Scheff, 1998), and by externalizing blame, shamed individuals can convert their shame to anger and avoid any conscious experience of the self-detrimental emotion. The result is a "shame-rage spiral," characterized by hostile responding to failure (H. B. Lewis, 1971).

Thus, individuals who are shame-prone also may be prone to making external attributions, but this does not mean that a particular external attribution for a negative event (e.g., blaming one's teacher for failure) will promote shame about that event. In fact, according to our model, people who report situational feelings of shame must be making internal, not external, attributions. It is nonetheless possible that the chronic experience of shame, elicited by repeated internal attributions, could promote the tendency to make defensive external attributions as a regulatory strategy. This process may account for the finding that ego-threats can lead to aggression (Bushman \& Baumeister, 1998). However, when individuals externalize, they do not consciously experience shame; in fact, the most likely reason for their externalizations is to avoid that conscious experience. As a result, shame and external attributions should be positively related only when both variables are assessed as chronic, dispositional tendencies. Thus, our second prediction states: The dispositional tendency to make external attributions will be positively related to proneness to shame, but external attributions for a particular event will not promote shame regarding that event (Hypothesis 2). We expect to find a positive relation between external attributions and shame in Study 1, in which chronic attributional styles and affective dispositions are assessed, and no relation in Studies 2 through 4, in which event-specific attributions and emotions are assessed.

\section{Shame Versus Guilt}

According to theoretical accounts, individuals experience guilt when they focus on negative aspects of their behavior- "the thing done or undone"-but they experience shame when they focus on negative aspects of themselves-the self who did or did not do it (H. B. Lewis, 1971, p. 30; M. Lewis, 2000; Tangney \& Dearing, 2002). Both emotions are elicited by internal attributions, but guilt results when unstable aspects of the self are blamed, and shame results from blaming the stable self.

The attributional dimension of stability concerns the extent to which the causes of events have a permanence beyond the specific event caused. A related dimension is controllability - the extent to which the causes of events can be changed. Controllable causes tend to be unstable, yet researchers have argued that the two dimensions are distinct (Weiner, 1991). The present research assesses and manipulates both stability and controllability and examines their relative importance. Both dimensions are typically studied in terms of two specific causesability and effort-where ability is a stable, uncontrollable cause and effort is an unstable, controllable cause (Weiner, 1985). ${ }^{1}$ Our third prediction states: Internal, stable, uncontrollable attributions (e.g., ability) will lead to greater shame than guilt, whereas internal, unstable, controllable attributions (e.g., effort) will lead to greater guilt than shame (Hypothesis 3).

Several lines of research support this prediction. Individuals who blame poor performance on ability (e.g., "I'm dumb") tend to respond with shame, whereas those who blame effort (e.g., "I didn't study for 
the exam") tend to respond with guilt (Brown \& Weiner, 1984; Covington \& Omelich, 1981; Jagacinski \& Nicholls, 1984; Russell \& McAuley, 1986; Weiner et al., 1982). In addition, the tendency to make internal, stable attributions for negative events is positively related to shame-proneness (Tangney et al., 1992), and individuals instructed to make counterfactual statements changing a stable aspect of their self-concept (e.g., "If only I were a better friend") reported greater shame and less guilt in response to a hypothetical scenario than those told to make counterfactuals changing their unstable behavior (e.g., "If only I had not flirted with his date"; Niedenthal, Tangney, \& Gavanski, 1994). Smith, Webster, Parrott, and Eyre (2002) found higher levels of shame than guilt in response to a hypothetical vignette about a student's incompetence (a stable, uncontrollable cause of negative performance).

However, research in this area is not entirely consistent. Russell and McAuley (1986) failed to replicate the link between internal, unstable attributions and guilt when they examined actual grades instead of hypothetical events. Tangney et al. (1992) found no relation between internal, unstable attributions and guilt-proneness. Brown and Weiner (1984) found that effort attributions were positively linked to shame. Furthermore, only a few of these studies assessed both shame and guilt, and those that did typically failed to support the prediction for both emotions.

\section{STUDY 1}

Study 1 tests our three hypotheses by examining the relation between chronic individual differences in attributional style and shame- and guilt-proneness.

Method

\section{PARTICIPANTS}

One hundred and fifty-three individuals ( $70 \%$ women) participated in exchange for course credit.

\section{MEASURES}

Attributional style. The 24-item Multidimensional Multiattributional Causality Scale for achievement events (MMCS; Lefcourt, von Baeyer, Ware, \& Cox, 1979) was used to assess the tendency to attribute events to effort, ability, luck, and context, separately for success and failure. Alpha reliabilities ranged from .65 to .77 , comparable to values typically reported (Lefcourt, 1991). Composite measures of internal and external attributions were computed from means of effort and ability (internal) and luck and context (external) scales. Attributions for success and failure were positively correlated $(r \mathrm{~s}=.44$ for effort and .30 for ability, both $p \mathrm{~s}<.05$ ), and effort attributions for success and failure were negatively correlated with ability attributions for failure $(r \mathrm{~s}=-.24$ and -.33 , respectively, both ps $<.05)$.

In addition to the MMCS, participants were asked, "How important was each of the following factors in determining the grades you have received in college so far?" Participants rated two internal causes ("amount of effort you put into school," "your ability") and six external causes ("chance/luck," "difficulty/ease of class/ school/environment," "ability of other students," "God/ higher power," "pressure from others to perform well and/or pressure from friends not to study," and "other factors external to you") using a scale ranging from 1 (not at all important) to 5 (extremely important). Composite measures of internal and external attributions were computed from these items. Ability attributions were correlated with MMCS ability attributions for success $(r=.21, p<.05)$, and effort attributions were correlated with MMCS effort attributions for success and failure $(r \mathrm{~s}=.37$ and .25 , respectively, both $p \mathrm{~s}<.05)$.

Implicit self-theories. Participants completed the eightitem Implicit Theories of Intelligence Scale and the three-item Implicit Theories of Others' Morality (IST; Dweck, 1999). Both scales were keyed toward an entity orientation, such that high scores represent a tendency to view one's intelligence and morality as stable (as opposed to unstable) traits. Alpha reliabilities were .88 (intelligence) and .59 (morality); the two scales correlated $.29(p<.05)$. IST intelligence (keyed toward an entity orientation) was positively correlated with MMCS ability attributions for success and failure (.24 and .25, respectively) and negatively with MMCS effort attributions for success and failure (-.46 and -.22, respectively, all $p \mathrm{~s}<.05)$ and effort attributions for performance in college $(-.27, p<.05)$. IST morality also was positively correlated with MMCS ability attributions for success and failure (.32 and .28 , respectively, $p s<.05)$.

Self-conscious emotional dispositions. Shame- and guiltproneness were assessed with the Test of Self-Conscious Affect (TOSCA; Tangney, Wagner, \& Gramzow, 1989). Participants rated the extent to which they would respond in a shame- and guilt-prone manner to 15 scenarios (e.g., "At work, you wait until the last minute to plan a project and it turns out badly") drawn from personal accounts of shame and guilt experiences. Alpha reliabilities were .77 (shame-proneness) and .70 (guiltproneness), comparable to values typically reported. Following Tangney et al. (1992), we computed measures of guilt-free shame and shame-free guilt by saving the standardized residuals from regression equations predicting shame from guilt and vice versa. These measures 
TABLE 1: Correlations of Locus Attributions With Guilt and Shame Proneness (Study 1)

\begin{tabular}{|c|c|c|c|c|}
\hline & \multicolumn{2}{|c|}{ Internal Attributions } & \multicolumn{2}{|c|}{ External Attributions } \\
\hline & $\begin{array}{c}\text { MMCS } \\
\text { Internality }\end{array}$ & $\begin{array}{c}\text { Internal } \\
\text { Attribution } \\
\text { for Grades }\end{array}$ & $\begin{array}{c}M M C S \\
\text { Externality }\end{array}$ & $\begin{array}{c}\text { External } \\
\text { Attribution } \\
\text { for Grades }\end{array}$ \\
\hline $\mathrm{Gu}$ & $.12(.04)$ & $.23^{*}\left(.18^{*}\right)$ & $-.05(-.27 *)$ & $.00(-.17 *)$ \\
\hline Shame & $.19 *\left(.16^{*}\right)$ & $.17 *(.08)$ & $.44 *(.51 *)$ & $.36 *(.40 *)$ \\
\hline
\end{tabular}

NOTE: $N=153$. Numbers in parentheses are part correlations with guilt controlling for shame and shame controlling for guilt. MMCS = Multidimensional Multiattribution Causality Scale.

$* p<.05$.

allowed us to examine each emotion's unique correlates while controlling for the overlap between the two scales $(r=.44)$.

Psychological adjustment. Self-esteem was assessed with the 16-item Self-Competence and Liking (SCL) scale (Tafarodi \& Swann, 2001; $\alpha=.91$ ). Optimism was assessed with the six-item Life Orientation Test (LOT; Scheier \& Carver, 1985; $\alpha=.84)$. Self-esteem and optimism are strongly negatively related to depression, neuroticism, and hopelessness (Robins, Tracy, Trzesniewski, Potter, \& Gosling, 2001; Scheier \& Carver, 1985) and, in conjunction with negative life events, can raise the risk of clinical depression (Andrews \& Brown, 1993; Roberts, Gotlib, \& Kassel, 1996). These findings suggest that optimism and self-esteem are good indicators of psychological adjustment and, by controlling for shared variance with these two variables, we can determine whether correlations between attributions and self-conscious emotions are due to their mutual overlap with psychological health.

\section{Results and Discussion}

\section{INTERNAL ATTRIBUTIONS AND}

SELF-CONSCIOUS EMOTIONS

Consistent with Hypothesis 1, the tendency to make internal attributions was positively associated with shame- and guilt-proneness (see Table 1). External attributions were negatively or not significantly related to guilt-proneness.

\section{SHAME-PRONENESS AND EXTERNAL ATTRIBUTIONS}

Consistent with Hypothesis 2, shame-proneness was positively correlated with the tendency to make external attributions (see Table 1). Thus, shame-proneness is positively related to both internal and external attributions. This pattern can be explained by our model, which suggests that internal attributions are the cognitive antecedents of shame and external attributions are the cognitive reappraisals used to regulate it. ${ }^{2}$

\section{DISTINCT ATTRIBUTIONS FOR SHAME AND GUILT}

Consistent with Hypothesis 3, shame-proneness was positively correlated with the tendency to make internal, stable, uncontrollable attributions, whereas guilt-proneness was positively correlated with the tendency to make internal, unstable, controllable attributions (see Table 2). For each attribution, the correlations with shame and guilt were significantly different from each other $(p s<.05)$. This pattern held for positive and negative events, both measures of attributional style, and implicit self-theories.

Of interest, this pattern held both for success and failure attributions. However, partial correlations between success attributions and shame- and guilt-proneness, controlling for failure attributions, were substantially reduced ( $r$ s ranged in magnitude from .01 to. 11), ${ }^{3}$ whereas partial correlations between failure attributions and shame- and guilt-proneness, controlling for success attributions, were highly similar to the corresponding zero-order relations ( $r$ ranged in magnitude from .30 to .48). Thus, for the most part, success attributions are related to shame and guilt because of shared variance with failure attributions, whereas failure attributions tend to have independent effects on shame and guilt.

Overall, these findings support Hypothesis 3 and suggest that shame and guilt are distinguished by attributions about the stability and controllability of internal causes. However, these findings differ somewhat from previous research (Tangney et al., 1992), possibly because earlier researchers assessed attributional style with a measure more closely linked to depression. To test whether our findings might be due to shared variance in psychological adjustment, we conducted partial correlations controlling for self-esteem and optimism. All significant correlations remained significant (partial $r$ ranged from .22 to .39 for shame and ability attributions and .26 to .35 for guilt and effort attributions). ${ }^{4}$

\section{LIMITATIONS}

Study 1 has several caveats. First, it relied entirely on correlations among self-reported variables so results may have been influenced by shared method variance. Second, although Hypothesis 2 was supported by the positive correlations between external attributions and shame-proneness, we did not test whether external attributions for a specific event promote shame about that event. Third, although the TOSCA is a reliable and wellvalidated measure (Tangney \& Dearing, 2002), its guiltproneness scale has been critiqued for assessing only the healthy components of guilt (Ferguson, in press; Kugler \& Jones, 1992). To address these issues, Study 2 replicated Study 1 using measures of attributional style, shame, and guilt that are less reliant on self-reports. 
TABLE 2: Correlations of Stability Attributions With Guilt and Shame Proneness (Study 1)

\begin{tabular}{|c|c|c|c|c|c|c|}
\hline & \multicolumn{4}{|c|}{ Internal, Stable Attributions } & \multicolumn{2}{|c|}{ Internal, Unstable Attributions } \\
\hline & $\begin{array}{c}\text { MMCS Ability } \\
\text { Attributions }\end{array}$ & $\begin{array}{l}\text { Ability Attribution } \\
\text { for Grades }\end{array}$ & $\begin{array}{c}\text { Implicit Self-Theory } \\
\text { of Intelligence }\end{array}$ & $\begin{array}{c}\text { Implicit Self-Theory } \\
\text { of Morality }\end{array}$ & $\begin{array}{l}\text { MMCS Effort } \\
\text { Attributions }\end{array}$ & $\begin{array}{l}\text { Effort Attribution } \\
\quad \text { for Grades }\end{array}$ \\
\hline Guilt & $-.13(-.34 *)$ & $.04(-.07)$ & $-.10(-.20 *)$ & $-.11\left(-.24^{*}\right)$ & $.30 *(.41 *)$ & $.28 *(.32 *)$ \\
\hline Shame & $.39 *(.50 *)$ & $.24 *(.25 *)$ & $.27 *(.35 *)$ & $.14 *(.21 *)$ & $-.16^{*}\left(-.32^{*}\right)$ & $.00\left(-.15^{*}\right)$ \\
\hline
\end{tabular}

NOTE: $N=153$. Numbers in parentheses are part correlations with guilt controlling for shame and shame controlling for guilt. MMCS = Multidimensional Multiattribution Causality Scale. Implicit self-theory scales were keyed toward an entity orientation.

$* p<.05$.

STUDY 2

Study 2 assessed college students' attributions for their academic performance and their emotional reactions to this performance. Attributions and emotions were assessed through content analysis of narrative responses to garner information participants may be disinclined to directly report, such as feelings of shame.

Method

\section{PARTICIPANTS}

Two hundred forty-nine undergraduate students $(64 \%$ women) were paid to participate in the study.

\section{MEASURES}

Participants were asked, "Think about your current college GPA [grade point average]. Describe how it makes you feel when you think about how well or poorly you have done so far in college." Responses were content-coded by an advanced student who was completing an honor's thesis on emotion. A second rater coded $20 \%$ of the responses to establish reliability.

Causal attributions. The rater was trained to answer the following question for each response: "How important does the participant think each of the following factors was in determining the grades he/she received in college?" Three causal factors-effort, ability, and external causes-were rated on a 5-point scale ranging from not at all important to very important. The rater also coded, "To what extent does the participant seem to feel like he/she has control over his/her grades in college?" on 5-point scales ranging from very slightly or not at all to extremely. ${ }^{5}$ Alpha reliabilities were .80 (effort), .51 (ability), .73 (external), and .64 (control). We took the mean of ability and effort to create an internal composite score.

Emotions. For each response, the rater coded guilt as "expressing a sense that he/she has done the wrong thing, feels badly about what he/she has done, focus on event that made him/her feel bad" and shame as "ashamed of him/herself, expressing a sense that his/her self is bad or a failure" using a 5-point scale ranging from very slightly or not at all to extremely. Alpha reliabilities were .58 (guilt) and .79 (shame). Shame and guilt correlated .11 (ns).

Perceptions of success or failure. Participants' perceptions of academic performance were assessed in two ways. First, narrative responses were coded for "the extent to which the participant views his/her academic performance as a success or failure" on a 5-point scale ranging from clearly a failure to clearly a success ( $\alpha$ reliability $=.92$ ). Second, participants responded to the question, "Would you consider your academic performance last semester a success or a failure?" by selecting one of four options: "clearly a failure," "somewhat of a failure," "somewhat of a success," or "clearly a success." The two measures correlated $.60(p<.05)$.

Psychological adjustment. Self-esteem was assessed with the 10-item Rosenberg (1965) Self-Esteem Scale (RSE; $\alpha=.91)$. Optimism was assessed with the LOT $(\alpha=.87)$. Depression was assessed with the 20-item Center for Epidemiological Studies Depression Scale (CES-D; Radloff, 1977; $\alpha=.91)$.

\section{Results and Discussion}

\section{LOCUS ATTRIBUTIONS AND SELF-CONSCIOUS EMOTIONS}

Consistent with Hypothesis 1, internal attributions for grades in college were positively correlated with feelings of guilt and shame in response to grades (see Table 3). Consistent with Hypothesis 2, external attributions were not correlated with the guilt or shame elicited by those grades. Together with the findings from Study 1, these results support the claim that external attributions are positively related to shame only when both attributions and emotions are assessed as chronic dispositions.

\section{DISTINCT ATTRIBUTIONS FOR SHAME AND GUILT}

Consistent with Hypothesis 3, individuals who attributed their grades to ability, an internal, stable, uncontrollable cause, tended to feel shame in response, whereas 
TABLE 3: Correlations of Content-Coded Attributions With Content-Coded Self-Conscious Emotions (Study 2)

\begin{tabular}{lccllll}
\hline & \multicolumn{2}{c}{$\begin{array}{c}\text { Locus } \\
\text { Attributions }\end{array}$} & & \multicolumn{2}{c}{$\begin{array}{c}\text { Stability } \\
\text { Attributions }\end{array}$} & \\
\cline { 2 - 3 } & Internal & External & & Ability & Effort & Feelings of Control \\
\hline Guilt & $.28^{*}$ & -.07 & & .02 & $.32^{*}$ & $.13^{*}$ \\
Shame & $.12^{*}$ & .00 & & $.15^{*}$ & .04 & $-.15^{*}$ \\
\hline
\end{tabular}

NOTE: $N=249$.

$* p<.05$.

those who attributed their grades to effort, an internal, unstable, controllable cause, tended to feel guilt (see Table 3). These correlations replicate those found in Study 1 and held for participants' feelings of control.

To test whether effects might be due to shared variance with psychological adjustment, we conducted partial correlations controlling for self-esteem, optimism, and depression. All significant zero-order correlations remained significant (partial $i s=.26$ for shame and ability and .26 for guilt and effort, both $p$ s $<.01$ ), replicating the findings from Study 1 and suggesting that psychological adjustment does not account for the attributionemotion relations.

We next used multiple regression analyses to test whether perceptions of performance moderated the correlations. For each emotion (shame, guilt), we entered effort attributions and coded performance as predictors in the first step and the interaction between effort and performance in the second step; we then repeated these analyses with ability and then repeated both sets using participants' own ratings of performance. The interaction term was not significant in predicting shame. In the analyses predicting guilt from effort attributions, the interaction term was significant and held for both coded performance $\left(B=-.12, p<.05, \Delta R^{2}=.013\right)$ and self-rated performance $\left(B=-.12, p<.05, \Delta R^{2}=.012\right)$, suggesting that effort attributions produced greater guilt when participants failed than when they succeeded.

\section{Conclusions}

These findings support all three hypotheses and are consistent with those of Study 1. However, given that both studies used correlational methods, we cannot know whether attributions and emotions are causally related. It is possible that correlations result from a spurious third factor influencing each dimension, such as an underlying personality disposition like neuroticism. This kind of trait might cause people to repeatedly make certain attributions (i.e., internal, stable) and experience certain self-conscious emotions (i.e., shame). We have addressed this issue by controlling for several potential confounds (self-esteem, optimism, and depression), but it is impossible to partial out every potential confound. Thus, in Study 3, we manipulated emotions.

STUDY 3

Study 3 manipulated emotional experiences and used content analysis to assess participants' appraisals for the shame and guilt they reported.

Method

\section{PARTICIPANTS AND PROCEDURE}

Eighty-six undergraduate students (83\% women) were asked to think of a real incident in which they felt either shame or guilt and respond to the open-ended question, "Tell in detail what happened to cause you to feel shame [guilt]." This task is a version of the well-established Relived Emotion Task (Ekman, Levenson, \& Friesen, 1983), which has been shown to manipulate emotional experiences and produce emotion-typical subjective feelings and physiology (Ekman et al., 1983; Levenson, 1992). This task may be particularly effective for selfconscious emotions. An event that caused fear may not reawaken the full fear experience when recalled, given that the elicitor is likely no longer present, but for shame and guilt the key elicitor-the self-is still present.

Emotions were manipulated between participants to avoid artificial inflation of differences between the conditions. Given that participants were not asked to directly contrast guilt and shame, or even informed that there was more than one condition, any differences found can be attributed to differences between the two emotions rather than to experimenter-demand. In addition, participants were not provided with definitions of shame or guilt so their conceptualizations of the emotions were not predetermined. Lay people typically show little consensus about the prototypical differences between the two emotions (Tangney \& Dearing, 2002), so any differences found are likely to be based on actual experiences and not on shared conceptual knowledge.

\section{MEASURES}

Four judges, blind to participants' emotion condition (guilt vs. shame), independently coded responses to each question. Judges were trained to use the coding scheme on several responses excluded from analyses and reached adequate levels of agreement for most of the dimensions coded (see below). Composite scores for each dimension were computed from mean ratings across all judges.

Type of event. Judges coded the extent to which the event that elicited the emotion was related to achievement (involving school, grades, exams, work-related 
events/behaviors), romantic relationships, family (involving family members), and personal (involving personal goals or morals, failure at an identity/self goal or expectation). Each narrative received a score for each event type, ranging from 1 (not at all this type of event) to 5 (very much this type of event). Alpha reliabilities were .96 (achievement), .92 (relational), .94 (familial), and .77 (personal).

Attributions. Judges coded for the presence of the following attributions: (a) locus: "Does the participant seem to think that the cause of the event is due to something about him/her or to something about other people or circumstances?" using a scale from 1 (completely due to other people or circumstances) to 5 (completely due to me); "Does he/she blame others who may have caused the eliciting event?" using a scale ranging from 1 (no one else blamed for the event) to 5 (clear statement that at least one other person is blamed); (b) stability: "In the future, if the eliciting event occurs again, does the participant think that this cause will again be present?" using a scale ranging from 1 (never present again) to 5 (will definitely be present again); and (c) controllability: "Does the participant feel like he/she was in control of the situation (or the cause) that elicited the emotion? In other words, does he/she seem to think that he/she could have prevented the event from occurring?" using a scale ranging from 1 (not at all in control) to 5 (completely in control). Alpha reliabilities were .68 (internal), .78 (external), .60 (stability), and .77 (controllability).

Results and Discussion

\section{EVENTS ELICITING SHAME AND GUILT}

Mean ratings across shame and guilt narratives were 2.78 (personal), 2.65 (relationships), 1.90 (familial), and 1.51 (achievement). A similar, but not identical, pattern emerged when we classified each narrative into the event category that was rated as most descriptive (i.e., that received the highest mean rating for that narrative): $36 \%$ relationships, $30 \%$ personal, $22 \%$ familial, and $12 \%$ achievement.

When we compared shame and guilt narratives, we found that shame was elicited more frequently by achievement events $(M=1.78, S D=1.41,16 \%$ vs. $M=$ $1.24, S D=.78,7 \%$ for guilt $)$ and personal events $(M=$ $3.09, S D=1.21,40 \%$ vs. $M=2.48, S D=.94,21 \%$ for guilt). Given that achievement and personal events are more private than relational and familial events, these findings are inconsistent with the traditional view that shame is a public emotion and guilt is private (e.g., Buss, 1980; Smith et al., 2002). However, other perspectives (including that espoused by our model) suggest that shame and guilt can have highly similar (and equally public or private) antecedents. ${ }^{6}$

\section{ATTRIBUTION-EMOTION RELATIONS}

Consistent with Hypothesis 1 , both shame- $(M=3.40$, $S D=.89)$ and guilt-eliciting events $(M=3.49, S D=.73)$ were likely to be attributed to internal causes. Consistent with Hypothesis 2, neither shame- $(M=1.94$, $S D=.95)$ nor guilt-eliciting events $(M=1.68, S D=.65)$ were likely to be blamed on others. Both shame and guilt events were more likely to be attributed to internal than external causes $(t s=5.43$ and 9.34 , respectively, both $p$ s $<.05)$. Consistent with Hypothesis 3, guilt events $(M=3.87, S D=.84)$ were more likely to be attributed to controllable causes than were shame events $(M$ $=3.26, S D=1.13 ; t=2.84, p<.05)$. Shame events $(M=$ $2.51, S D=.62)$ were slightly more likely to be attributed to stable causes than were guilt events $(M=2.43, S D=$ $.58)$, but the difference was not statistically significant. This null finding may be due to the fact that the stability dimension had a reliability of only .60, attenuating the observed effect. It is also possible, however, that controllability provides a better conceptualization of the distinction between effort and ability, at least as these causes relate to shame and guilt. In Studies 1 and 2 , we assessed only the particular causes and not the underlying dimensions and therefore cannot know whether findings were due to differences in controllability, stability, or both. In Study 4, we again examine both dimensions and compare their effects.

In summary, Study 3 generally supports our hypotheses. The findings extend those of Studies 1 and 2 by manipulating emotions, assessing controllability and stability separately, and examining these relations in nonacademic contexts. Regardless of whether people feel shame about a failed relationship or a failed exam, they feel shame (and not guilt) at least partly because they attribute the event to something uncontrollable about themselves.

Study 3 has several limitations. First, it is possible that participants' descriptions of their emotional experiences were based on their conceptual knowledge of the two emotions rather than on the feelings that actually occurred during the experiences. However, our use of a between-subjects design minimizes concerns about this issue because lay people typically conflate and confuse shame and guilt (Tangney \& Dearing, 2002). A reliance on conceptual knowledge of the two emotions would be unlikely to produce the differences found; rather, given that they were not aware of our plans to compare shame and guilt, participants who based their narratives on conceptual knowledge would be more likely to describe highly similar and overlapping events and attributions. Second, although the experimental manipulation of shame and guilt helps rule out some third variable interpretations, we cannot determine whether attributions cause emotions or vice versa. Third, the ambiguous 
results regarding stability prohibit any conclusion about its relevance to the shame-guilt distinction. Study 4 addresses these limitations by manipulating locus, stability, and controllability attributions.

STUDY 4

Method

\section{PARTICIPANTS}

One hundred and fifteen undergraduate students (82\% women) participated in exchange for course credit.

\section{PROCEDURE AND DESIGN}

Participants read four vignettes about a hypothetical college student's performance on a final exam, a frequently experienced, emotionally evocative event for most participants. They were instructed to read each scenario and "think about how you would feel if you were actually living through this experience. Try to imagine the thoughts and feelings you would have if you were actually in this situation."

Participants were randomly assigned to read one of two sets of vignettes. Set 1 included four vignettes manipulating the locus (internal vs. external) and stability (stable vs. unstable) of the cause of the event. Set 2 included four vignettes manipulating the locus and controllability (controllable vs. uncontrollable) of the cause of the event. Each vignette was two to three sentences long, in the second-person singular ("you”) form, and described a failure experience in either math or English (varied within subjects). For example, the internal, controllable vignette was as follows: "You recently had an important math exam but you didn't bother to study for it. You just found out that you did badly on the exam." In contrast, the internal, uncontrollable vignette was as follows: "You have never had much natural talent (i.e., been smart) in English. You recently had an important English exam, and you studied hard for it, but it still seemed very difficult to you. You just found out that you did badly on the exam." After reading each vignette, participants made attributions about the causes of the event and rated the emotions they would feel if they had actually experienced the event.

\section{INDEPENDENT VARIABLES}

Locus attributions. Locus was manipulated within subjects, such that half the vignettes described events caused by internal factors (effort, ability) and half caused by external factors (luck, other people).

Stability attributions. Stability was manipulated within subjects, such that half the vignettes in Set 1 described events caused by stable factors (ability, chronic luck) and half caused by unstable factors (effort, temporary luck). However, only participants in the Set 1 condition read the vignettes manipulating stability.

Controllability attributions. Controllability was manipulated within subjects, such that half the vignettes in Set 2 described events caused by controllable factors (effort, choice of class) and half caused by uncontrollable factors (ability that cannot be overridden by effort, other person whose impact cannot be overridden by effort). Information about (low) effort was included in the uncontrollable condition to emphasize that the outcome occurred despite the student's efforts. In contrast, the high stability condition (in Set 1) did not provide information about the student's attempts at control. Only participants in the Set 2 condition read the vignettes manipulating controllability. Thus, by treating participation in Set 1 versus Set 2 as a between-subjects manipulation, we can test whether stability or controllability has a larger effect on the shame-guilt distinction.

\section{DEPENDENT VARIABLES: OUTCOME EMOTIONS}

Participants were instructed to "rate the extent to which you would feel each of the following emotions: anger, anxiety, embarrassment, fear, frustration, guilt, hostile, sadness, and shame," on a scale ranging from 1 (not at all) to 7 (extremely).

\section{MANIPULATION CHECK}

After each vignette, participants were asked, "If you were in this situation, to what extent do you think each of the following reasons would explain why you did badly on the exam?" Participants rated the following factors: "how hard you studied" [internal, unstable, controllable], "your academic ability (i.e., how smart you are)" [internal, stable, uncontrollable], "how lucky or unlucky you were" [external, unstable, uncontrollable], and "how hard (or easy) this class and/or the professor is" [external, stable, uncontrollable]. The rating scale ranged from 1 (not at all important) to 7 (very important).

\section{Results and Discussion}

\section{MANIPULATION CHECK}

The results suggest that manipulations were effective. For the Set 1 vignettes, the two internal causes were rated higher in the internal attribution condition, $F(1,57)=55.98, p<.05$, for effort, and $F(1,57)=70.36$, $p<.05$, for ability, and the two external causes were rated higher in the external attribution condition, $F(1$, $57)=21.94, p<.05$, for luck, and $F(1,57)=34.66, p<$ .05 , for class/professor difficulty. Effort ratings were higher in the unstable condition, $F(1,57)=9.39, p<$ .05 , and ability ratings were higher in the stable condition, $F(1,57)=17.02, p<.05$. 


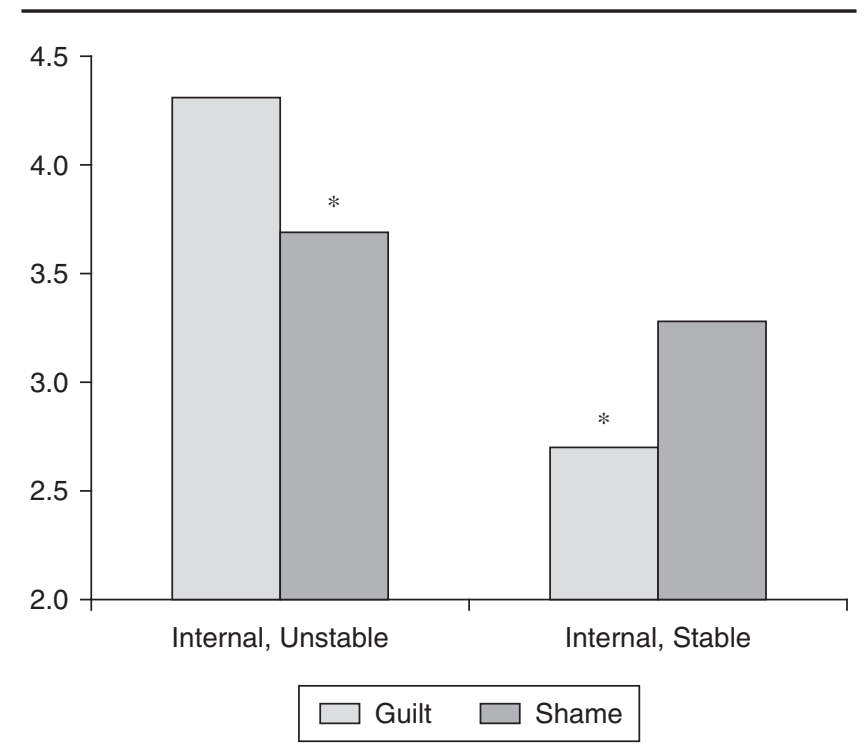

Figure 1 Interaction between emotion (shame vs. guilt) and stability (stable vs. unstable) attributions in the internal attribution NOTE: $N=57$. condition (Study 4).

$* p<.05$.

For the Set 2 vignettes, the two internal causes were rated higher in the internal attribution condition, $F(1$, $57)=9.64, p<.05$, for effort, and $F(1,57)=4.05, p<$ .05 , for ability, and the external cause of class/professor difficulty was rated higher in the external attribution condition, $F(1,57)=79.87, p<.05$. Effort ratings were higher in the controllable condition, $F(1,57)=68.42$, $p$ $<.05$, and ability ratings were higher in the uncontrollable condition, $F(1,57)=9.78, p<.05$.

\section{SELF-CONSCIOUS VERSUS NON-SELF-CONSCIOUS EMOTIONS}

We conducted a two-way ANOVA on the Set 1 vignettes, with emotion (self-conscious: embarrassment, guilt, shame vs. non-self-conscious: anger, anxiety, fear, frustration, sadness, hostile) and locus (internal vs. external) treated as within-subjects factors. ${ }^{7}$ Consistent with Hypothesis 1, an Emotion $\times$ Locus Cross-Over interaction emerged, $F(1,57)=55.91, p<.05$, suggesting that internal attributions led to greater self-conscious $(M=2.20)$ and fewer non-self-conscious $(M=1.90)$ emotions than did external attributions ( $M=1.71$ for self-conscious, 2.13 for non-self-conscious). Consistent with Hypothesis 2, participants reported greater shame about the situational failure in response to internal $(M=3.48)$ than external $(M=2.64)$ attributions, $F(1,57)=25.08, p<.05$.

\section{GUILT VERSUS SHAME}

Stability attributions. A three-way ANOVA on the Set 1 vignettes, with emotion (shame vs. guilt), locus (internal

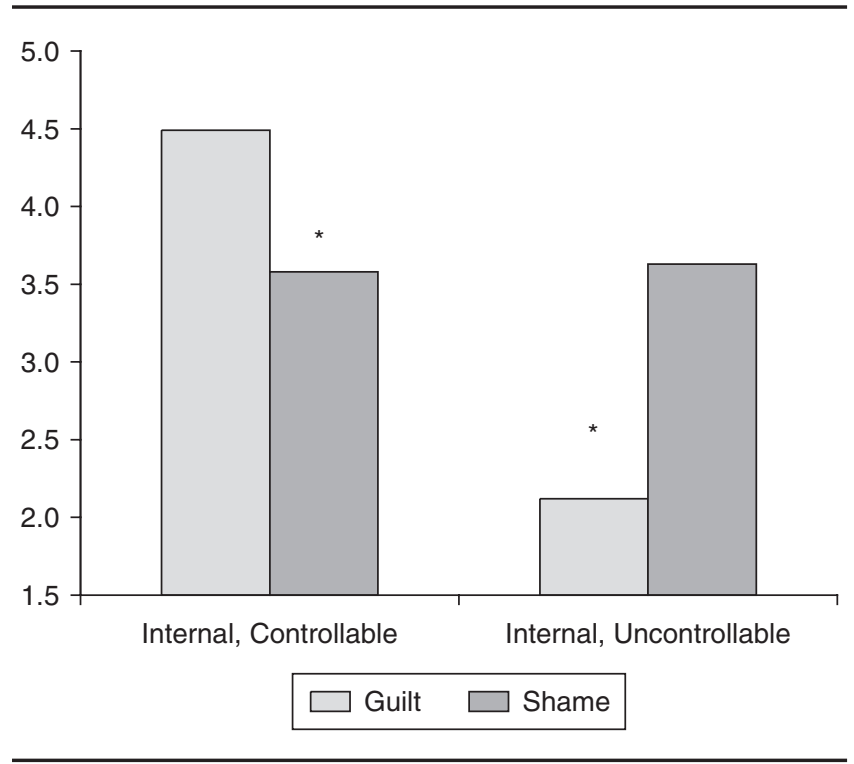

Figure 2 Interaction between emotion (shame vs. guilt) and controllability (controllable vs. uncontrollable) attributions in the internal attribution condition (Study 4).

NOTE: $N=57$.

$* p<.05$.

vs. external), and stability (stable vs. unstable) as withinsubject factors, revealed a three-way interaction, $F(1$, $57)=4.97, p<.05$. To better understand this interaction, and given the finding that shame and guilt were greater following internal than external attributions, we next examined responses to internal attribution scenarios only. We found the predicted Emotion $\times$ Stability interaction, $F(1,57)=18.80, p<.05$, reflecting the fact that internal, stable attributions led to greater shame than guilt and internal, unstable attributions led to greater guilt than shame (see Figure 1).

Controllability attributions. A three-way ANOVA on the Set 2 vignettes, with emotion (shame vs. guilt), locus (internal vs. external), and controllability (controllable vs. uncontrollable) as within-subjects factors, revealed a three-way interaction, $F(1,56)=44.47, p<.05$. Given that shame and guilt were greater following internal than external attributions, we next examined responses to internal attribution scenarios only. The predicted Emotion $\times$ Controllability interaction emerged, $F(1$, $56)=59.23, p<.05$, reflecting the fact that internal, uncontrollable attributions for negative events led to greater shame than guilt and internal, controllable attributions for negative events led to greater guilt than shame (see Figure 2).

Stability versus controllability. The Emotion $\times$ Controllability interaction $\left(\eta^{2}=44 \%\right)$ was significantly larger than the Emotion $\times$ Stability interaction $\left(\eta^{2}=8 \%\right)$, as 
indicated by a three-way interaction between emotion (guilt vs. shame), attribution (stable/uncontrollable vs. unstable/controllable), and vignette type (controllability vs. stability; $F=8.72, p<.05$ ). Thus, our controllability manipulation distinguished between shame and guilt more strongly than did our stability manipulation. However, these results may be unique to the particular manipulations used in this study and do not necessarily indicate that controllability is more crucial to distinguishing shame and guilt than stability.

\section{GENERAL DISCUSSION}

The present findings support three predictions derived from our theoretical model of self-conscious emotions. First, all four studies showed that internal attributions lead to self-conscious emotions (Hypothesis 1). When people blame themselves for failure, they tend to experience a self-conscious emotion such as shame, whereas when they blame others, they tend to experience a non-self-conscious emotion, such as anger (Russell \& McAuley, 1986). The replication of this pattern using different methods across multiple studies helps resolve inconsistencies in the previous literature, such as the failure to find a consistent relation between internal attributions for college grades and self-conscious emotional responses (e.g., Russell \& McAuley, 1986).

Second, Study 1 supports the link between shameproneness and chronic external attributions and Studies 2, 3, and 4 support the absence of this link for event-specific shame and attributions (Hypothesis 2). In Study 1, shame-proneness was positively related to the tendency to make external attributions. In Studies 2, 3, and 4, where externalizations were assessed as attributions for a particular event and shame as an emotional response to that event, this relation did not emerge. Our findings are thus consistent with the idea that shame-prone individuals regulate this painful emotion by blaming others for failure (H. B. Lewis, 1971; Scheff, 1998). This regulatory style may successfully decrease the overall frequency of conscious shame experiences, but when shame does occur, it will still be in response to internal, stable, and uncontrollable attributions for negative events (i.e., a regulatory failure), as is suggested by the findings of Studies 2, 3, and 4 .

These findings also have implications for the way guilt is regulated. The finding that guilt (controlling for shame) was negatively correlated with the tendency to make external attributions in Study 1 suggests that individuals do not regulate feelings of guilt through externalization. Instead, guilt-prone individuals tend to make internal attributions, which would lead only to more guilt. Although this account leaves open the question of how individuals do regulate their guilt, one possibility is that guilt is more effectively countered through behavioral than cognitive (i.e., reappraisal) regulation. Guilt motivates reparative behaviors (e.g., apology, future hard work) oriented toward fixing the situation (Tangney \& Dearing, 2002). If effective, these behaviors would ameliorate the guilt and reduce the need for reappraisal. In contrast, if shame results from blaming stable, uncontrollable aspects of the self, then changing one's unstable, controllable behaviors is not likely to cease the emotional experience, at least in the short term. Rather, ashamed individuals may need to adopt a long-term strategy of behavioral modification (e.g., working toward becoming a different kind of person) or make the cognitive reappraisals implicated by the present research (i.e., externalize or reattribute to an internal but unstable, controllable cause).

Third, all four studies showed that attributing failure to an internal, uncontrollable cause, such as ability, is positively related to shame (but not guilt) and attributing failure to an internal, unstable, and controllable cause, such as effort, is positively related to guilt (but not shame). This pattern emerged from diverse methodologies and thus may allow for firmer conclusions than previous studies that produced inconsistent findings (e.g., Brown \& Weiner, 1984; Russell \& McAuley, 1986; Tangney et al., 1992). Previous studies that failed to support this link either used less reliable means of assessing attributions or did not directly compare attributions for shame versus guilt.

The present findings extend previous research on attribution-emotion links in several ways. First, convergence of results across a range of methods, which both manipulate and measure attributions and emotions, indicates the robustness of the findings. Second, replication of the findings when attributions were manipulated points to a causal relation between attributions and emotions. Although the experimental studies did not manipulate attributions for actual events, research suggests that manipulating hypothetical appraisals tends to produce the same results as evoking online emotional experiences (Robinson \& Clore, 2001). Moreover, studies using experience sampling methods to assess online appraisals and emotions also have replicated emotion-appraisal links found previously in hypothetical manipulation studies (Tong et al., 2006). In fact, in the present research, the results of Study 4 replicate those of Studies 1 to 3, where actual emotions and emotional reactions were assessed.

Third, we assessed or manipulated three attribution dimensions that are theoretically relevant to self-conscious emotions: locus, stability, and controllability. As a result, the present findings reveal new complexities. In Study 1, the effort/ability distinction differentiated 
among self-conscious emotions, but it was unclear whether the dimension of stability or controllability was at the root of this effect. In Study 2, effort, ability, and feelings of control were each important, and in Studies 3 and 4, controllability had a stronger effect than stability. Thus, it seems that attributions about the controllability of internal causes distinguish between shame and guilt, but the precise role of stability is less clear. It is also possible that the small differences in the role of stability found across studies reflect idiosyncrasies of the coders or particular dimensions coded. Another possibility, relevant to Study 4, is that our controllability manipulation was more powerful than our stability manipulation. We operationalized uncontrollable causes as causes that the participant cannot change despite explicit efforts to do so ("I can't change it even when I try") and thus provided greater information than in the operationalization of stability ("I can't change it"). In our view, this additional information ("even when I try") reflects the critical distinction between controllability and stability, but future studies should replicate the finding using an alternate means of manipulating these attributions.

It is also possible, however, that controllability and stability are inextricably entwined and cannot be disentangled. Although previous theorists have pointed to causal factors such as laziness as evidence that a cause can be controllable but stable (see Note 1), if people can control their laziness, then it can change and is thus unstable. Laziness may therefore be seen as controllable but not actually controlled, which raises philosophical questions about the precise meaning of different attributions. However, such fine conceptual distinctions are unlikely to be relevant to the folk attribution process, and we see little evidence that lay attributors distinguish between stable and uncontrollable causes.

Dweck's (1999) theory of implicit self-theories raises a complementary issue: Incremental theorists may view their ability as unstable, which would challenge the assumption that ability attributions constitute attributions to a stable factor. We addressed this issue by assessing implicit self-theories in Study 1. Results showed that implicit self-theories were not related to shame or guilt when variance in ability and effort attributions was statistically removed, suggesting that entity theorists tend to experience shame and incremental theorists tend to experience guilt because they tend to make ability and effort attributions, respectively.

Fourth, we assessed or manipulated both shame and guilt in four different studies, allowing us to directly compare the attributions that elicit these two emotions and thereby provide some clarity to a literature that is fraught with inconsistencies. Most previous research included only one of the two emotions, and the few studies that included both tended to produce either inconsistent findings across studies (e.g., Russell \& McAuley, 1986) or confirmed their predictions for one emotion but not the other (e.g., Brown \& Weiner, 1984; Tangney et al., 1992).

Fifth, we assessed attribution-emotion links in both achievement and nonachievement contexts. Studies 1, 2 , and 4 focused on the achievement domain because it is a common elicitor of shame and guilt. However, the findings were replicated in Study 3 when participants wrote about emotions generated by a range of events. The majority of descriptions (88\%) in Study 3 were not about achievement and all effects remained significant when participants who wrote primarily about achievement were excluded from analyses.

One limitation of the present research is that many of the findings depend on self-report methodologies. We tried to circumvent this concern by using content coding of narrative descriptions (Studies 2 and 3) and manipulating emotions (Study 3) and attributions (Study 4) but the present findings should nonetheless be replicated using non-self-report measures of emotion. However, the current state of the field makes such studies difficult to conduct. Researchers have yet to identify a distinct nonverbal expression of guilt and there is conflicting evidence on whether shame has a distinct expression (e.g., Haidt \& Keltner, 1999; Tracy \& Robins, 2006). One possible direction for future work would be to assess physiological markers of these emotions; Dickerson, Gruenwald, and Kemeny (2004) have found that proinflammatory cytokine and cortisol levels are elevated when individuals experience shame but not general distress. Another possibility would be to code for more complex behaviors, such as approachversus avoidance-oriented movements.

\section{Implications}

\section{IMPORTANCE OF LOCUS}

As predicted, when people blame themselves for a negative event they tend to feel shame or guilt, whereas when they blame others, they tend to feel angry (e.g., Russell \& McAuley, 1986). Thus, attributions of causal locus are essential to the appraisal process in self-conscious emotion elicitation. Theories that do not include locus cannot fully explain why one individual becomes angry after losing his job while another becomes ashamed.

\section{IMPORTANCE OF STABILITY AND CONTROLLABILITY}

Shame is generated when people blame the stable, uncontrollable self for failure, whereas guilt occurs from blaming an unstable, controllable action taken by the self. One implication of this finding is that we can abandon the long-held idea that there is no difference between shame and guilt (e.g., Tomkins, 1963). The two emotions are elicited by similar events, but the present 
research suggests that it is not the eliciting event that distinguishes shame and guilt but the way the event is appraised.

A second implication is in regard to the adaptive function of the two emotions. The presence of distinct eliciting appraisals and outcome behaviors suggests that shame and guilt evolved to serve unique needs. The behavioral outcomes of shame and guilt are, to some extent, diametrically opposed: Shame promotes hiding and escape, whereas guilt promotes approach and reparation (Ketelaar \& Au, 2003; Tangney \& Dearing, 2002). Integrating these findings with those from the present research, we can speculate about the unique evolutionary problems each emotion might address. If an individual fails because of something he or she could have controlled or changed, the best solution is to make reparations and work harder in the future. Guilt may be the affective mechanism that mediates internal, controllable attributions and behaviors of confession, apology, and improved performance. In contrast, if failure is the result of something internal, stable, and uncontrollable, the best solution is to escape the situation and avoid further attempts at the task. Given that escape and avoidance are typically associated with shame (Shiota \& Keltner, 2005; Tangney, Miller, Flicker, \& Barlow, 1996), we can begin to understand why humans might have evolved to experience these two emotions as distinct. Continued effort when success would never arrive could cost valuable resources, and the exposure of a stable flaw might promote antagonism from others. The best response is escape to avoid social rejection and the associated costs to fitness. ${ }^{8}$

This functional account does not necessitate that individuals always respond to guilt by attempting to repair the situation and to shame by withdrawing or externalizing blame. Rather, these are the basic action tendencies associated with the two emotions; they may or may not be expressed behaviorally during each particular emotional incident, depending on individual differences and situational contingencies. From an evolutionary perspective, each emotion should activate a coordinated set of action tendencies that serve specific adaptive functions but that, in many contexts, may be regulated and not converted into actual behaviors.

Finally, these findings have implications for the role of shame in depression (e.g., Kendler, Hettema, Butera, Gardner, \& Prescott, 2003; Tangney \& Dearing, 2002). Previous research suggests that internal, stable, global attributions for failure contribute to depression (Peterson \& Seligman, 1984). Based on the present findings, we can speculate that shame may mediate the link between helpless attributional style and depression.

In conclusion, the present research provides empirical support for our theoretical model of the cognitive antecedents of shame and guilt and thereby converges with the growing literature on the complexity of self-conscious emotions (e.g., Tracy, Robins, \& Tangney, in press).

\section{NOTES}

1. Ability may be unstable for those who believe that they can improve their abilities and effort may be stable when conceived of as a personality trait, such as laziness (Dweck, 1999; Weiner, 1985). Nonetheless, in the present research, we conceptualize effort and ability in their most prototypical form, distinguished by the dimensions of stability and controllability.

2. To further examine whether dispositional shame-proneness promotes a tendency toward externalizing, we assessed three traits that are likely to result from externalizing tendencies-anger, hostility, and aggression (using the Aggression Questionnaire; Buss \& Perry, 1992)-in a new sample $(N=1,631,66 \%$ women). Shameproneness was positively correlated with all three traits $(r \mathrm{~s}$ ranged from .26 to .40 , all $p s<.05$ ), whereas guilt-proneness was negatively correlated with all three traits ( $r$ r ranged from -.27 to -.34 , all $p \mathrm{~s}<$ $.05)$. This pattern supports our finding that externalizations are uniquely associated with the regulation of shame and that individuals who experience chronic guilt manage their feelings without succumbing to anger and aggression.

3. There was a single exception, a negative correlation between effort attributions for success and shame, which was not mediated by failure attributions. This may point to the importance of attributing success to effort, an adaptive style that apparently buffers individuals from shame. This same exception emerged for the partial correlation with failure attributions controlling for success, in this case not significant.

4. Optimism was positively correlated with Multidimensional Multiattribution Causality Scale (MMCS) effort attributions for success and failure $(\mathrm{r}=.32$ and .22 , respectively) and negatively correlated with MMCS ability attributions for failure $(r=-.34)$. Self-esteem was positively correlated with MMCS effort attributions for success $(r=.38)$ and negatively with MMCS ability attributions for failure $(r=-.48$, all $p s<.05)$.

5 . Feelings of control correlated with attributions to effort $(r=.43$, $p<.01)$ but not with attributions to ability $(r=.04, n s)$.

6. This finding also is consistent with Baumeister, Stillwell, and Heatherton's (1994) view of guilt as a social emotion.

7. These analyses replicated using scales based on a more stringent criterion for non-self-conscious emotions, aligning with the notion of basic emotions: fear, anger, and sadness (i.e., Ekman, 1992).

8. Another potentially adaptive response would be appeasement, that is, signaling that the individual is aware of his or her flaw so punishment is unnecessary. Some researchers suggest that shame is associated with appeasement behaviors (Gilbert, in press; Tangney \& Dearing, 2002) but others hold that, in humans, embarrassment is the emotion that more directly serves this purpose (Shiota \& Keltner, 2005).

\section{REFERENCES}

Andrews, B., \& Brown, G. W. (1993). Self-esteem and vulnerability to depression: The concurrent validity of interview and questionnaire measures. Journal of Abnormal Psychology, 102, 565-572.

Baumeister, R. F., Stillwell, A. M., \& Heatherton, T. F. (1994). Guilt: An interpersonal approach. Psychological Bulletin, 115, 243-267.

Brown, J., \& Weiner, B. (1984). Affective consequences of ability versus effort ascriptions: Controversies, resolutions, and quandaries. Journal of Educational Psychology, 76, 146-158.

Bushman, B. J., \& Baumeister, R. F. (1998). Threatened egotism, narcissism, self-esteem, and direct and displaced aggression: Does selflove or self-hate lead to violence? Journal of Personality and Social Psychology, 75, 219-229.

Buss, A. H. (1980). Self-consciousness and social anxiety. San Francisco: Freeman.

Buss, A. H., \& Perry, M. (1992). The aggression questionnaire. Journal of Personality and Social Psychology, 63, 452-459. 
Covington, M. V., \& Omelich, C. L. (1981). As failures mount: Affective and cognitive consequences of ability demotion in the classroom. Journal of Educational Psychology, 73, 796-808.

Dickerson, S. S., Gruenewald, T. L., \& Kemeny, M. E. (2004). When the social self is threatened: Shame, physiology, and health. Journal of Personality, 72, 1191-1216.

Dweck, C. S. (1999). Self-theories: Their role in motivation, personality, and development. Philadelphia: Psychology Press/Taylor \& Francis.

Ekman, P. (1992). An argument for basic emotions. Cognition and Emotion, 6, 169-200.

Ekman, P., Levenson, R. W., \& Friesen, W. V. (1983). Autonomic nervous system activity distinguishes among emotions. Science, 221, 1208-1210.

Ferguson, T. (in press). Madness to methods and purpose in pain: Studying the beneficial and adverse consequences of shame and guilt. In J. L. Tracy, R. W. Robins, \& J. P. Tangney (Eds.), The selfconscious emotions: Theory and research. New York: Guilford.

Gilbert, P. (in press). The evolution of shame as a marker for relationship security: A biopsychosocial approach. In J. L. Tracy, R. W. Robins, \& J. P. Tangney (Eds.), The self-conscious emotions: Theory and research. New York: Guilford.

Haidt, J., \& Keltner, D. (1999). Culture and facial expression: Openended methods find more expressions and a gradient of recognition. Cognition and Emotion, 13, 225-266.

Hudley, C. A. (1992). Attributions for pride, anger, and guilt among incarcerated adolescents. Criminal Justice and Behavior, 19, 189-205.

Jagacinski, C. M., \& Nicholls, J. G. (1984). Conceptions of ability and related affects in task involvement and ego involvement. Journal of Educational Psychology, 76, 909-919.

Keltner, D., \& Buswell, B. N. (1996). Evidence for the distinctness of embarrassment, shame, and guilt: A study of recalled antecedents and facial expressions of emotion. Cognition and Emotion, 10, 155-171.

Kendler, K. S., Hettema, J. M., Butera, F., Gardner, C. O., \& Prescott, C. A. (2003). Life event dimensions of loss, humiliation, entrapment, and danger in the prediction of onsets of major depression and generalized anxiety. Archives of General Psychiatry, 60, 789-796.

Ketelaar, T., \& Au, W. T. (2003). The effects of feelings of guilt on the behaviour of uncooperative individuals in repeated social bargaining games: An affect-as-information interpretation of the role of emotion in social interaction. Cognition and Emotion, 17, 429-453.

Kugler, K., \& Jones, W. H. (1992). On conceptualizing and assessing guilt. Journal of Personality and Social Psychology, 62, 318-327.

Kuppens, P., Van Mechlen, I., Smits, D. J. M., \& De Boek, P. (2003). The appraisal basis of anger: Specificity, necessity, and sufficiency of components. Emotion, 3, 254-269.

Lazarus, R. S. (1991). Emotion and adaptation. New York: Oxford University Press.

Lefcourt, H. M. (1991). Locus of control. In J. P. Robinson, P. R. Shaver, \& L. S. Wrightsman (Eds.), Measures of personality and social psychological attitudes (pp. 413-499). San Diego, CA: Academic Press.

Lefcourt, H. M., von Baeyer, C. L., Ware, E. E., \& Cox, D. J. (1979). The multidimensional-multiattributional causality scale: The development of a goal specific locus of control scale. Canadian Journal of Behavioral Science, 11, 286-304.

Levenson, R. W. (1992). Autonomic nervous system differences among emotions. Psychological Science, 3, 23-27.

Lewis, H. B. (1971). Shame and guilt in neurosis. New York: International Universities Press.

Lewis, M. (2000). Self-conscious emotions: Embarrassment, pride, shame, and guilt. In M. Lewis \& J. M. Haviland-Jones (Eds.), Handbook of emotions (2nd ed., pp. 623-636). New York: Guilford.

Niedenthal, P. M., Tangney, J. P., \& Gavanski, I. (1994). "If only I weren't" versus "If only I hadn't": Distinguishing shame and guilt in counterfactual thinking. Journal of Personality and Social Psychology, 67, 585-595.

Peterson, C., \& Seligman, M. E. (1984). Causal explanations as a risk factor for depression: Theory and evidence. Psychological Review, 91, 347-374.

Radloff, L. S. (1977). The CES-D Scale: A self-report depression scale for research in the general population. Applied Psychological Measurement, 1, 385-401.

Roberts, J. E., Gotlib, I. H., \& Kassel, J. D. (1996). Adult attachment security and symptoms of depression: The mediating role of dysfunctional attitudes and low self-esteem. Journal of Personality and Social Psychology, 70, 310-320.
Robins, R. W., Tracy, J. L., Trzesniewski, K. H., Potter, J., \& Gosling, S. D. (2001). Personality correlates of self-esteem. Journal of Research in Personality, 35, 463-482.

Robinson, M. D., \& Clore, G. L. (2001). Simulation, scenarios, and emotional appraisal: Testing the convergence of real and imagined reactions to emotional stimuli. Personality and Social Psychology Bulletin, 27, 1520-1532.

Roseman, I. J. (1991). Appraisal determinants of discrete emotions. Cognition and Emotion, 5, 161-200.

Rosenberg, M. (1965). Society and the adolescent self-image. Princeton, NJ: Princeton University Press.

Russell, D., \& McAuley, E. (1986). Causal attributions, causal dimensions, and affective reactions to success and failure. Journal of Personality and Social Psychology, 50, 1174-1185.

Scheff, T. J. (1998). Shame in the labeling of mental illness. In P. Gilbert \& B. Andrews (Eds.), Shame: Interpersonal behavior, psychopathology, and culture (pp. 191-205). Oxford, UK: Oxford University Press.

Scheier, M. F., \& Carver, C. S. (1985). Optimism, coping, and health: Assessment and implications of generalized outcome expectancies. Health Psychology, 4, 219-247.

Shiota, M. N., \& Keltner, D. (2005). What do emotion words represent? Psychological Inquiry, 16, 32-37.

Smith, H. S., Webster, J. M., Parrott, W. G., \& Eyre, H. L. (2002). The role of public exposure in moral and nonmoral shame and guilt. Journal of Personality and Social Psychology, 83, 138-159.

Tafarodi, R. W., \& Swann, W. B. (2001). Two-dimensional self-esteem: Theory and measurement. Personality and Individual Differences, 31, 653-673.

Tangney, J. P. (1991). Moral affect: The good, the bad, and the ugly. Journal of Personality and Social Psychology, 61, 598-607.

Tangney, J. P. (1992). Situational determinants of shame and guilt in young adulthood. Personality and Social Psychology Bulletin, 18, 199-206.

Tangney, J. P., \& Dearing, R. L. (2002). Shame and guilt. New York: Guilford.

Tangney, J. P., Miller, R. S., Flicker, L., \& Barlow, D. H. (1996). Are shame, guilt, and embarrassment distinct emotions? Journal of Personality and Social Psychology, 70, 1256-1269.

Tangney, J. P., Wagner, P., \& Gramzow, R. (1989). The test of self-conscious affect. Unpublished measure, George Mason University, Fairfax, VA.

Tangney, J. P., Wagner, P., \& Gramzow, R. (1992). Proneness to shame, proneness to guilt, and psychopathology. Journal of Abnormal Psychology, 101, 469-478.

Tomkins, S. S. (1963). Affects, imagery, consciousness. New York: Springer.

Tong, E. M. W., Bishop, G. D., Enkelmann, H. C., Diong, S. M., Khader, M., \& Ang, J. (2006). The use of ecological momentary assessment to test appraisal theories of emotion. Emotion, 5, 508-512.

Tracy, J. L., \& Robins, R. W. (2004). Putting the self into self-conscious emotions: A theoretical model. Psychological Inquiry, 15, 103-125.

Tracy, J. L., \& Robins, R. W. (2006). The nonverbal expression of pride: Evidence for cross-cultural recognition. Manuscript submitted for publication.

Tracy, J. L., \& Robins, R. W. (in press) The self in self-conscious emotions: A cognitive appraisal approach. In J. L. Tracy, R. W. Robins, \& J. P. Tangney (Eds), The self-conscious emotions: Theory and research. New York: Guilford.

Tracy, J. L., Robins, R. W., \& Tangney, J. P. (in press).The self-conscious emotions: Theory and research. New York: Guilford.

Vistica, G. L. (2001, April 29). What happened in Thanh Phong. New York Times Magazine, pp. 50-68.

Weiner, B. (1985). An attributional theory of achievement motivation and emotion. Psychological Review, 92, 548-573.

Weiner, B. (1991). An attributional look at explanatory style. Psychological Inquiry, 2, 1-10.

Weiner, B., Graham, S., \& Chandler, C. (1982). Pity, anger, and guilt: An attributional analysis. Personality and Social Psychology Bulletin, 8, 226-232.

Weiner, B., \& Kukla, A. (1970). An attributional analysis of achievement motivation. Journal of Personality and Social Psychology, 15, 1-20.

Received March 17, 2005

Revision accepted April 3, 2006 